\title{
La casa de las fincas cafeteras como patrimonio agroindustrial colombiano en riesgo
}

\section{Coffee farmhouses as Colombian agro-industrial heritage at risk}

\author{
Ángela María Santa Quintero*
}

Citar este artículo como: Santa Quintero, A. M. (2018). La casa de las fincas cafeteras como patrimonio agroindustrial colombiano en riesgo. Revista Nodo, 12(24), 74-88.

\section{Resumen}

El presente artículo se origina a partir de uno de los trabajos de campo realizados durante mis estudios académicos para la Maestría en Restauración de monumentos arquitectónicos de la Pontificia Universidad Javeriana de Bogotá. En este texto se exponen algunos de los hallazgos alcanzados para entonces, remozados con información actualizada y pertinente sobre las casas de dos fincas cafeteras y un sector poblado, situados en el Departamento de Caldas, Colombia. Los tres objetos de estudio se incluyen con el fin de analizar y valorar el patrimonio agroindustrial de la zona cafetera; la vivienda como unidad productiva y la cultura asociada a ella como herencia viva. Aunque el propósito inicial fue identificar en los diferentes niveles de caficultura la tradición, el conocimiento, las técnicas y la memoria de trabajo, la arquitectura y el paisaje industrial, como elementos del patrimonio cultural en el territorio; en este artículo sólo se presenta el análisis de las viviendas campesinas de la zona de estudio, de los peligros que se cierne sobre ellas y por ende, del riesgo que existe para el paisaje cultural cafetero como patrimonio. Para ello se habla, en primera medida, sobre las nociones de patrimonio industrial, y la metodología empleada, para luego abordar las características físicas de las casas cafeteras, sus valores patrimoniales y las posibles amenazas que enfrenta actualmente el patrimonio agroindustrial en la zona cafetera del país.

Palabras clave: Patrimonio agroindustrial, Paisaje cultural, Arquitectura cafetera, Patrimonio de la zona cafetera.

\section{Abstract}

This article originates from one of the ffieldwork projects carried out during my academic studies for the master's degree in Restoration of Architectural Monuments at the Pontifical Xavierian University of Bogotá. This text presents some of the findings achieved then and renovated with updated and relevant information of the two farmhouses and a rural village, located in the Department of Caldas, Colombia. The three objects of study are included in order to analyze and assess the agro-industrial heritage of the coffee zone; the house as a productive unit and the culture associated with it as a living heritage. Although, the initial purpose was

Fecha de recibo: 3 de septiembre de 2018 - Fecha de aceptación: 25 de octubre de 2018

* Arquitecta. Magíster en Restauración de monumentos arquitectónicos. Profesora de tiempo completo de la Universidad Antonio Nariño. Correo electrónico: angelasanta@uan.edu.co 
to identify knowledge, skills, the memory of work, architecture and industrial landscape as elements of cultural heritage in that territory at different levels of traditional coffee growing. In this article, only the corresponding analysis of the farmhouse in the area estudied, is reflected. Therefore, it discusses, firstly, the notions of industrial heritage, the methodology used, and then addresses the physical characteristics of the coffee farmhouse, its heritage values and the possible threats currently facing the agro-industrial heritage in the country's coffee zone.

Keywords: Agro-industrial heritage, Cultural landscape, Coffee area architecture, Heritage of the coffee zone.

\section{Introducción}

El trabajo inicial que sustenta parte de este artículo, realizó en su momento un acercamiento al patrimonio cultural cafetero en Colombia, visto como una herencia viva y activa en constante evolución que aborda todas las expresiones culturales, tangibles e intangibles de la población; forjadas, a partir de una actividad económica productiva específica, y que incide en los elementos naturales y del cultivo y beneficio del café en Colombia. A través de la observación directa, se intentó redescubrir los elementos patrimoniales presentes en las actividades productivas cafeteras, al tomar como objetos de estudio tres bienes (dos fincas y una vereda cafetera en el departamento de Caldas), con el fin de identificar la manera en que la tradición, el conocimiento, las técnicas de producción, la memoria de trabajo, la arquitectura y el paisaje se encuentran presentes, dn los diferentes niveles de caficultura, en ese momento y ahora, como elementos de desarrollo económico y cultural del territorio.

El presente artículo solo hará alusión a lo relacionado con la casa de la finca cafetera como unidad productiva y reservorio material de todo el legado cultural de esta región. En ese sentido, se intentará valorar aquellos elementos patrimoniales fundamentales de la identidad cultural mediante el abordaje de las casas de dos fincas cafeteras y una centralidad rural, con el ánimo de destacar la importancia que tiene su preservación y salvaguarda, en medio del escenario actual donde la afluencia de turismo hacia el eje cafetero de Colombia en los últimos siete años se ha incrementado de manera notoria, poniendo en riesgo la conservación del patrimonio cultural de la zona.

El Paisaje Cultural Cafetero de Colombia -en adelante PCC- fue reconocido por el Ministerio de Cultura de Colombia mediante Resolución 2079 de 2011 (Mincultura, 2011) como Patrimonio Cultural de la Nación y como bien inscrito en la Lista de Patrimonio Mundial de la Organización de la Naciones Unidas para la Educación la Ciencia y la Cultura -UNESCO- (2001); sin embargo, el control sobre las intervenciones que se están realizando en los bienes inmuebles, lugares rurales, centros poblados y espacio público, no es eficaz o pertinente. Y ello se evidencia, entre otras cosas, en las adecuaciones de las viviendas campesinas, la eliminación o mutilación de infraestructura tradicional para el beneficio del café, la introducción de ornamentación inconsistente con la herencia cultural o falsos históricos, entre muchas otras intervenciones inadecuadas que están poniendo en riesgo la salvaguarda del patrimonio cultural del eje cafetero en Colombia, ya que se llevan a cabo sin la observancia de la normativa de cultura nacional vigente (Decreto 1080 de 2015) y en consecuencia, este patrimonio está sufriendo una rápida transformación y deterioro.

\section{Patrimonio agroindustrial: una noción teórica}

Diversos procesos industriales y, en general, las actividades humanas asociadas a ellos hacen parte del patrimonio cultural de una sociedad; sus evidencias, nos permiten entender las relaciones de producción y el tipo de sociedad que mueven las fuerzas de trabajo. Son testimonios de las actividades cotidianas: su economía, las expresiones culturales, las 
materias primas utilizadas y los productos finales que se obtienen. La interpretación del pasado, con base en el estudio de la herencia tangible, intangible y natural, en el caso del patrimonio industrial, nos permite comprender y documentar los procesos sociales que han tenido lugar en un territorio.

La noción internacional que expresa la carta de Nizhny Tagil, del Comité Internacional para la Conservación y Defensa del Patrimonio Industrial (TICCIH, 2003), sostiene que la evidencia material de los cambios sociales posee un valor humano universal que debe reconocerse, estudiarse y conservarse, así como el conocimiento que surge a partir del trabajo y el ingenio humano; el cual se transmite a generaciones siguientes, lo que se constituye en patrimonio industrial intangible. Así mismo, esta Carta señala que el valor del patrimonio industrial radica en ser testimonio del trabajo humano, de la vida cotidiana de las comunidades y de las transformaciones sociales, el cual debe conservarse como un conjunto de bienes y sus contextos, para que sea posible leer la historia completa de un territorio determinado.

Aguilar (1998) por su parte, anota que el patrimonio industrial está representado en aquellos bienes relacionados con las nuevas necesidades económicas de la sociedad, aquellas obras humanas que tienen una función práctica que provienen del pensamiento humano. Aclara que esta definición no solo incluye la arquitectura industrial, sino que también está representada por los sectores o lugares industriales, todo tipo de estructura propia de la actividad industrial, por los procedimientos constructivos y uso de materiales y las obras, que no sólo son muestra del ingenio humano y del uso de los materiales de cada momento histórico sino que además responden a estas nuevas necesidades sociales que en consecuencia modificaron drásticamente los territorios.

El patrimonio industrial contiene un trascendente valor social y narra las vidas de hombres y mujeres que han transformado la sociedad con su trabajo cotidiano, proporcionando un importante sentimiento de identidad colectivo. El patrimonio agroindustrial cafetero en Colombia contiene el conjunto de bienes que dan cuenta de los cambios de la sociedad y sus territorios, que para este caso particular, se da a finales del siglo XIX, con el inicio de la actividad cafetera en los territorios de la colonización antioqueña (Londoño, 2002).

Desde las definiciones anteriores, el patrimonio industrial podría comprender las siguientes categorías:

Patrimonio industrial tangible:

- Arquitectura industrial: Espacios que contienen las actividades humanas de producción y estructuras que soportan los medios de producción o que contienen un alto valor científico y son muestra del desarrollo tecnológico de la humanidad después de la era industrial; por ejemplo el empleo de la guadua, los beneficiaderos de café, heldas ${ }^{1}$, tolvas, bodegas, galpones, silos, viviendas, haciendas, cuarteles, alimentaderos, carreteras, acueductos o infraestructura eléctrica.

- Bienes muebles u objetos que son testimonio del desarrollo científico y muestra de la evolución tecnológica de la sociedad, como maquinaria, equipos, utensilios, herramientas o el mismo el producto final; elementos que requieren de alguna forma de energía para su operación o construcción: Despulpadoras, tanques de lavado, canastos "cocos", garabatos ${ }^{2}$, el jeep willys o básculas.

Patrimonio industrial intangible:

- Memoria del trabajo humano: es el conocimiento del "cómo se hace el trabajo", y transmitido por la herencia familiar de un trabajador a otro o

1 "Elba o Helda es el secadero de café hecho de madera y cubierto con techo de zinc. Costa de un piso construido a poca altura del suelo, para colocar debajo, cajones de madera en forma de gavetas que se deslizan sobre rieles que las conducen bajo techo." (Federación Nacional de Cafeteros de Colombia, 2018)

2 Garabatos: construidos en madera, forman la ensilladura de la bestia para montar la carga de café (una carga son dos sacos a cada lado, es decir $125 \mathrm{~kg}$ en total). 
de una generación a otra; también es la cultura obrera, las formas de vida y sus costumbres. Es el razonamiento científico y su aplicación en la producción y desarrollo de tecnología, aspectos que permiten entender la evolución de la sociedad y el proceso del pensamiento humano. Hacen parte de patrimonio intangible industrial, por ejemplo, la agilidad para realizar la recolección manual del café y la transmisión de ese conocimiento, la tecnificación del cultivo, el diseño y cálculo de un puente, la cultura que genera una comunidad obrera en un territorio o la divulgación de la cultura cafetera colombiana a través de la comercialización del grano en el mundo.

Patrimonio Industrial Mixto:

- Paisajes industriales: son aquellos escenarios de la memoria colectiva que contienen elementos de la industrialización humana y su entorno, por ejemplo el paisaje que genera el cultivo industrializado del café y que son el telón de fondo de la vida cotidiana de los pobladores de esta región.

- Patrimonio agroindustrial: es aquel que combina la actividad productiva humana con la naturaleza y su transformación. Traslada el desarrollo tecnológico y científico del territorio urbano al rural. La tecnificación del sector agrario muestra claramente el nacimiento de la era industrial alrededor del mundo. Tenemos por ejemplo de patrimonio agroindustrial, la vivienda y el beneficiadero de café como unidad productiva; una extensión de tierra cultivada así como las tradiciones y costumbres de las familias y los pueblos cafeteros.

\section{Metodología}

El trabajo de campo se desarrolló en la zona rural del departamento de Caldas, en las veredas La Pola del municipio de Manizales y las veredas La Plata y El higuerón del municipio de Palestina en el departamento de Caldas. Con el fin de observar los elementos patrimoniales que pudieran caracterizar la cultura cafetera en Caldas en el marco del patrimonio industrial colombiano, se tomaron tres sitios de observación:

- La primera finca visitada fue La Soledad, ubicada en la vereda La Plata del municipio de Palestina, catalogada para este trabajo como de mediana producción cafetera.

- La segunda fue la hacienda La Ermita, en las veredas La Plata y El Higuerón del municipio de Palestina, catalogada para este trabajo como de gran producción cafetera.

- Por último se visitó la vereda La Pola, como centralidad rural de pequeños caficultores.

En cada visita se realizó un levantamiento fotográfico teniendo en cuenta aspectos como la infraestructura física, el cultivo, las labores y elementos del beneficio del café, la arquitectura y el paisaje. En lo posible se intentó obtener información de fuentes primarias de los actores locales, con el fin de incorporar elementos culturales intangibles, como historia, costumbres y memoria de trabajo de cada lugar, lo que enriqueció sustancialmente el informe.

Además de lo anterior, en el caso de este artículo, se realizó una revisión bibliográfica con el fin de remozar los datos de campo obtenidos durante los años 2005 y 2006, para elaborar un panorama actual del estado del patrimonio cafetero y las problemáticas a las cuales se enfrenta hoy.

\section{El patrimonio vivo y activo y el PCC}

La cultura de la zona cafetera es un patrimonio vivo y activo, motor fundamental del desarrollo económico de miles de familias en Colombia. La evolución de las técnicas del cultivo del café muestra que esta actividad económica ha condicionado la forma de vida de grandes comunidades en Colombia, sus expresiones culturales, su modo de vida y costumbres y las relaciones de producción; conformando un patrimonio histórico y cultural que se mantiene vivo, activo y en constante desarrollo. El patrimonio agroindustrial cafetero de esta región es muestra de la adopción e introduc- 
ción de técnicas derivadas de la era industrial. La apropiación social de este patrimonio es un factor constante como acto consciente de la población. De tal forma las comunidades de la zona cafetera entienden que su actividad económica, origen de su sustento, está lleno de elementos de herencia y tradición cultural.

El paisaje de la zona cafetera no es solo el que se puede disfrutar como espectador distante, sino el que se observa desde la finca, la casa y el sitio de beneficio y el cultivo. Para quienes crecieron allí, éste se convierte en parte de su esencia vital y emotiva, condicionando su forma de vida, de pensamiento y sus expresiones culturales. El paisaje agroindustrial da cuenta de las transformaciones hechas sobre el territorio por los seres humanos a través de la historia y como han forjado su supervivencia por medio de las prácticas agrícolas. La UNESCO inscribió el 25 de junio de 2011 al Paisaje Cultural Cafetero de Colombia dentro de la Lista de Patrimonio Mundial (Unesco, 2001). El Ministerio de Cultura de Colombia en concordancia con la descripción de la Unesco, agregó lo siguiente:

El PCC reúne en su zona principal áreas específicas de 47 municipios y 411 veredas, y en su área de amortiguamiento, cuatro municipios y 447 veredas de los departamentos de Caldas, Quindío, Risaralda y Valle del Cauca, ubicadas en las ramificaciones Central y Occidental de la cordillera de los Andes. Sobre estos sistemas montañosos se han desarrollado representativas zonas de producción de café que constituyen un conjunto reconocido por sus atributos, las relaciones entre sus habitantes y su herencia cultural. Por sus condiciones de "localización, relieve, clima y suelos, esta región presenta un elevado número de hábitats de interés estratégico para la conservación de la diversidad biológica". (...)indispensables para la conservación de la biodiversidad mundial(...) Este modelo social y económico ha configurado una región con un alto grado de unidad cultural, expresada en un patrimonio cultural material en el que se destacan las técnicas constructivas tanto de los asentamientos urbanos como de las viviendas cafeteras rurales, así como un patrimonio cultural inmaterial (...)heredada de la colonización antioqueña, (...) Esta región ha sido tradicionalmente reconocida a nivel nacional e internacional como el Eje Cafetero y, más recientemente, como la Ruta del Café, a raíz de una campaña que busca promocionar a la zona a nivel nacional e internacional (Mincultura, 2018). (Negrilla fuera de texto original).

\section{La casa y el beneficio del café: infraestructura incorporada a la vivienda como unidad productiva}

Los pequeños caficultores de la zona estudiada conservan muchas de las técnicas para el beneficio del cafe ${ }^{3}$, que incluyen espacios y estructuras como las heldas, de variadas tipologías de construcción, las cuales obedecen a una combinación de diseños heredados, adaptaciones formuladas por los técnicos de los comités de cafeteros ${ }^{4} \mathrm{y}$ la introducción de elementos y sistemas constructivos únicos que se ajusten a las necesidades particulares de cada finca, condiciones topográficas, estructura espacial de la casa e imaginación constante. Podría decirse que no existe ninguna helda igual a otra, aunque todas se rigen por la misma filosofía de funcionamiento.

El elemento constante en todas las construcciones de esta región cafetera es la guadua, usada como elemento estructural, de cerramiento, de ornamentación, aplicada en todos los sistemas constructivos y en todos los espacios de la casa: el beneficiadero, corrales, cercas, escaleras de

3 Beneficio del café: "Conjunto de operaciones realizadas para transformar el café cereza en pergamino seco. Beneficiadero (beneficio) Técnicamente consiste en la serie de pasos o etapas de procesamiento a las que se somete el café para quitar o eliminar todas sus capas o cubiertas de la forma más eficiente sin afectar su calidad y su rendimiento. Es una transformación primaria del grano." (Federación Nacional de Cafeteros de Colombia, 2018)

4 Los Comités Departamentales y Municipales de Cafeteros son los encargados de la organización y la representación de los cafeteros ante la Federación Nacional de Cafetero de Colombia. (2018) 
acceso y hasta utensilios, siendo un material versátil y muy resistente a todo tipo de esfuerzo que además crece rápidamente y en abundancia en los lechos de las sistemas hídricos de la región. Las heldas casi siempre se usan también como cubierta del beneficiadero o de algún espacio utilitario. Los silos de secado se utilizan en fincas de mayor producción, también de variadas formas y capacidades.

A pesar de sus innumerables variantes y adaptaciones particulares a la geomorfología, la vivienda cafetera caldense (y del todo el eje cafetero) siempre recurre a una misma solución conceptual del espacio, dividiéndolo en cuatro tiempos:

- El acceso: normalmente se configura como plazoleta, zona de recibo, jerárquica, centralizada y generosa, que invita a seguir a un espacio cubierto de la casa sin imponer barreras, trata de ofrecer protección al visitante siendo un lugar público.

- El corredor: cubierto con el alero del techo y semicerrado con la chambrana de macana ${ }^{5}$. Es un lugar de estancia, para lo público, lo social que permite esa suave transición entre el exterior y el interior, que además distribuye hacia el tercer tiempo que son los espacios privados.

- La crujía de los espacios privados: contiene las habitaciones que se comunican algunas entre sí internamente y cada una con salida al corredor, estos son los espacios cerrados, privados y que solo pertenecen a la familia. En uno de los extremos de esta crujía se ubica el comedor, lugar semiprivado, jerárquico de contenidos simbólicos patriarcales y remarcable ornamentación (calados en puertas y ventanas de postigo). Le sigue la cocina, espacio privado $y$ semioculto.

- Áreas de trabajo: se localiza detrás de la crujía privada, son zonas de servicios y áreas de trabajo, escondidas de lo público, donde se ubicó hasta

5 Chambrana de macana: en el eje cafetero de Colombia se conoce como el pasamanos de los corredores exteriores de la casa, construido con balaustres de palma de cera.
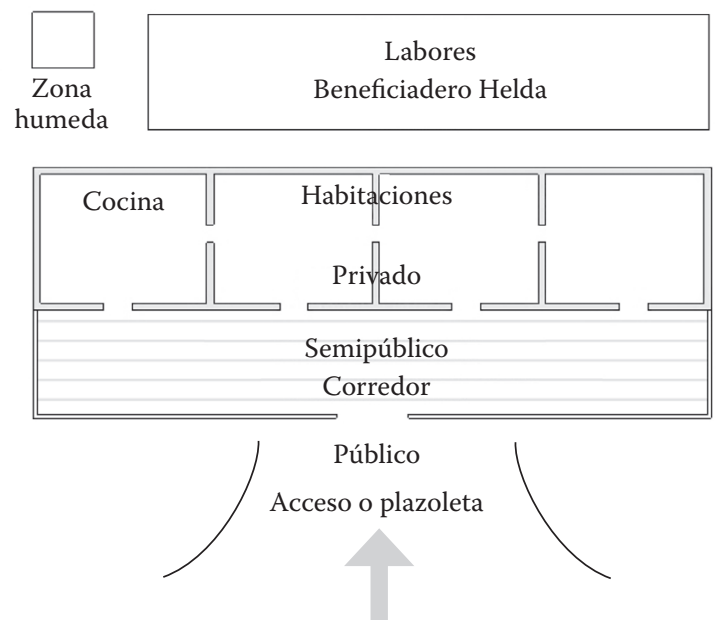

Figura 1. Esquema de organización espacial de la casa cafetera en Caldas y en el eje cafetero. Fuente: elaboración propia

hace unos 40 años el baño y las zonas húmedas y donde hasta hoy se implanta el beneficiadero, bodegas, cuartos de almacenamiento, gallineros y huertas (Figura 1).

\section{Bienes objeto de estudio: antecedentes histórico-geográficos}

Las fincas objeto de estudio, como ya se ha advertido en las páginas anteriores, están localizadas en el departamento de Caldas y fueron las siguientes: La soledad, ubicada en la vereda La plata del municipio de Palestina; la hacienda La Ermita, en las veredas La plata y El higuerón del municipio de Palestina; y la vereda La Pola, como centralidad rural de pequeños caficultores (Figuras 2 y 3 ).

Un breve esbozo histórico del departamento de Caldas muestra que desde principios del siglo XIX, la colonización antioqueña buscó nuevos territorios para la implantación de centros urbanos y la explotación de los recursos naturales. El acondicionamiento de tierras consistía en la tala de los bosques, drenaje de suelos y siembra de cultivos. Muchas familias antioqueñas poblaron rápidamente las zonas menos malsanas del norte del antiguo departamento del Cauca (Londoño, 2002) hoy conocido como el eje cafetero (Figura 4). 


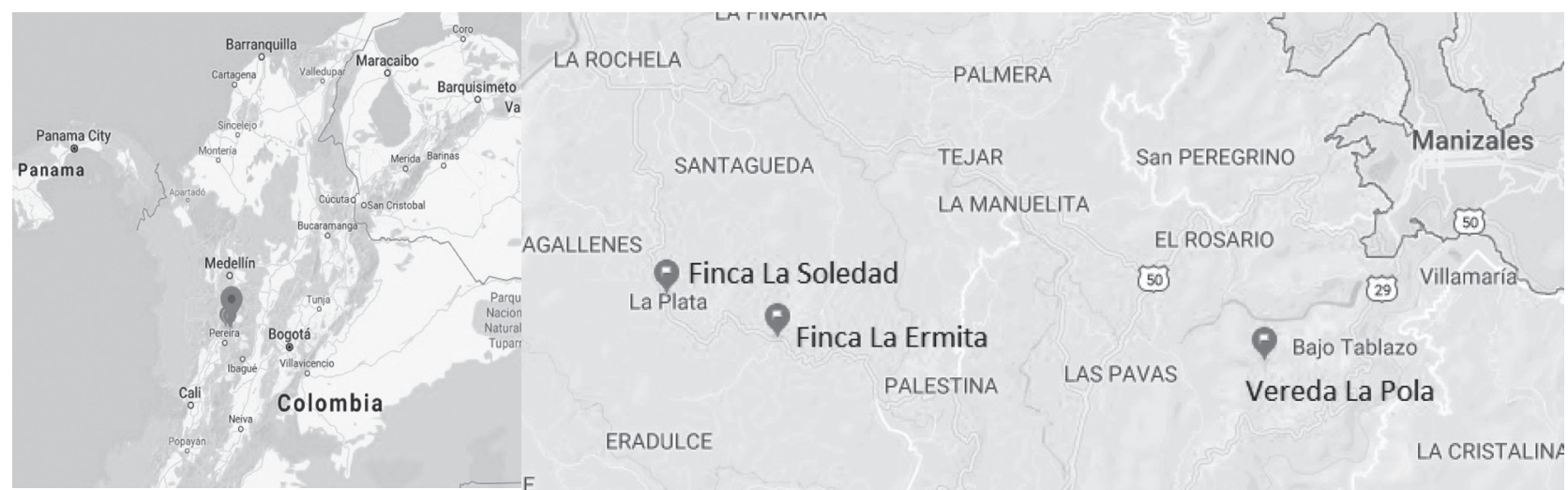

Figuras 2 y 3. Localización del departamento de Caldas y de la zona de estudio. Fuente: Google maps. Sep. 2018

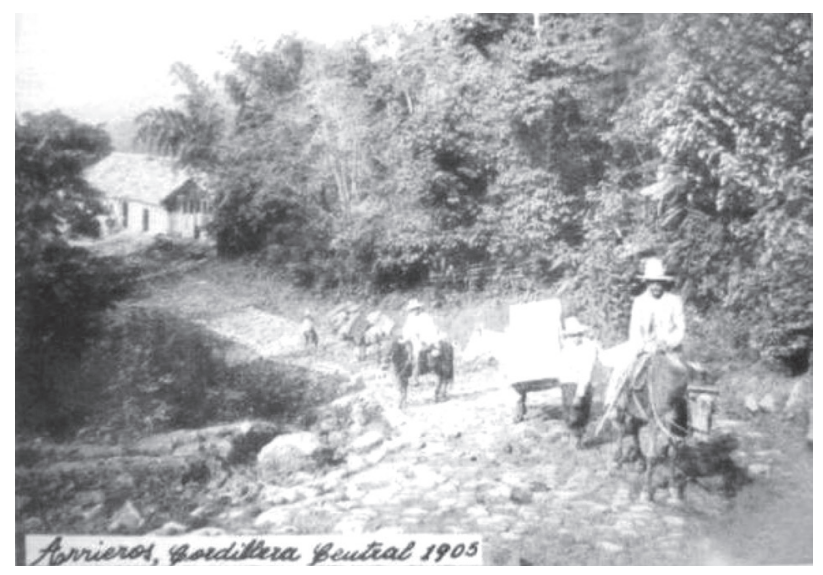

Figura 4. Arrieros cordillera central, 1905. Fuente: Cien años de Caldas. (Márquez, 2005)

Entre 1800 y 1850, La ruta de la colonización antioqueña (Figura 5) pasaba por Aguadas, Pácora, Salamina, Aranzazu y Neira. Desde Neira en 1849, salió la comisión fundadora de Manizales como gran centro poblacional de la nueva colonia. Entre 1850 y 1900, la colonización continúa hacia el sur, fundando pueblos como Chinchiná y Palestina luego Pereira y Armenia, entre muchos otros pertenecientes al gran Caldas (Parsons, 1950). Colonos provenientes en su mayoría de Marinilla, Titiribí y Rionegro, se asentaron en Manizales y Palestina.

\section{Finca La soledad}

La casa de esta finca fue construida en la década de 1920 (Figuras 6 y 7). A lo largo del tiempo ha sufrido importantes transformaciones y sobre todo una reconstrucción casi completa luego de que

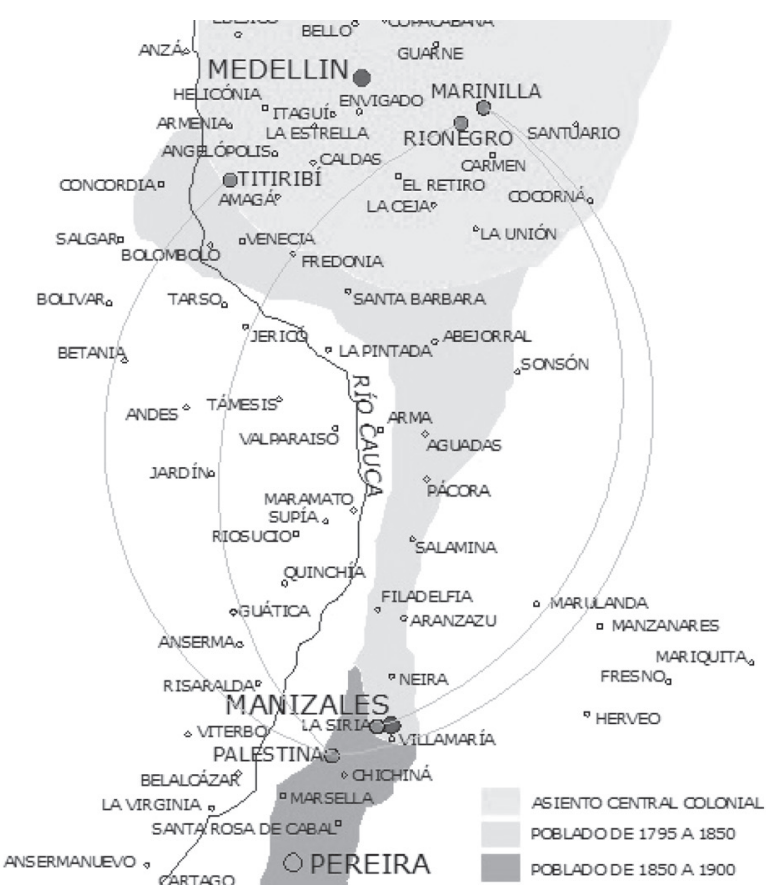

Figura 5. Flujo de la colonización antioqueña. Fuente: Elaboración propia con información tomada de La colonización antioqueña en el occidente de Colombia. (Parsons, 1950).

en 1970 presentara un grave estado estructural en las maderas y la guadua. Todos los pisos de tabla y muros de bahareque fueron nuevamente construidos conservando las mismas técnicas y empleando materiales similares (Giraldo, F. Entrevista, 2015). ${ }^{6}$

La estructura de cubierta de madera en escuadría, guadua en cepa y esterilla y teja de barro en

6 Giraldo, Fabiola. Entrevista, Manizales, agosto de 2015. 


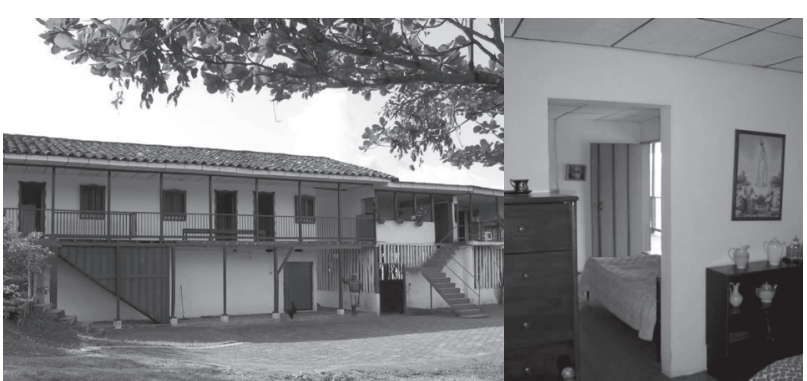

Figuras 6 y 7. La casa de la Finca la Soledad. Fuente: elaboración propia

cubierta, fue en gran parte reutilizada. La disposición espacial se conservó en términos generales, recortando un poco el ancho de la crujía de habitaciones. Además se construyó la vivienda de los agregados y el nuevo beneficiadero que estaría más acorde con las nuevas necesidades productivas de la finca, luego de la tecnificación, es decir, la introducción de la variedad Colombia ${ }^{7}$. El entrepiso de madera clavada a tope sobre listones transversales de madera, sostenidos por vigas cargueras, descansan sobre columnas de madera que transmiten la carga hasta los cimientos de concreto (en reemplazo de la tradicional piedra de basamento); todos estos sistemas constructivos heredados de la arquitectura de la colonización antioqueña.

A pesar de las reconstrucciones y adecuaciones hechas a lo largo de los años, la espacialidad de la casa corresponde a la distribución tipológica de la vivienda cafetera: la carretera que conduce a la casa desemboca en una amplia plazoleta que permitía anteriormente la llegada y amarre de las bestias (y ahora a vehículos). El primer piso utilizado como área de almacenamiento de café y atención a los asuntos de trabajo (Figura 8). El segundo piso de la casa está dedicado a la vivienda de la familia, a la cual se accedía por una rampa, reemplazada hoy por unas escaleras que desem-

7 Variedad Colombia: es una especie de café formada al mezclar la semilla proveniente de las progenies más sobresalientes seleccionadas. Esta variedad es más resistente a la roya y no requiere bosques para el sombrío, lo que aumenta sustancialmente la rentabilidad del cultivo (Federación Nacional de Cafetero de Colombia, 2018). bocan en el corredor, sitio semipúblico y que distribuye a la crujía de las habitaciones privadas que están comunicadas entre sí internamente, lo que facilita el control y cuidado de la familia.

La vivienda de los agregados donde además se alimenta a los trabajadores está conexa a la casa principal. En la parte posterior de la casa está la zona de trabajo: gallinero, cultivo de gansos, huerta, árboles frutales, producción de abono orgánico y la helda (Figuras 9 y 10).

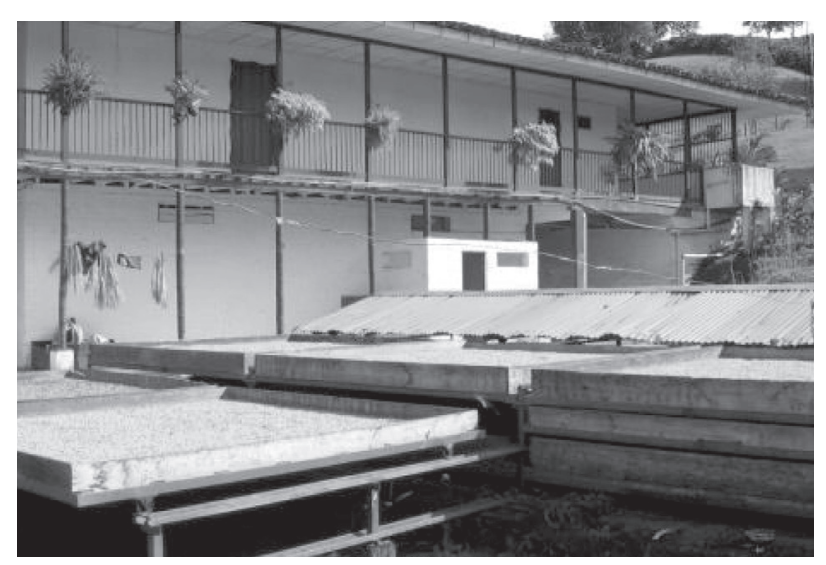

Figura 8. Lugares de trabajo. Casa de la Finca la Soledad. Fuente: elaboración propia
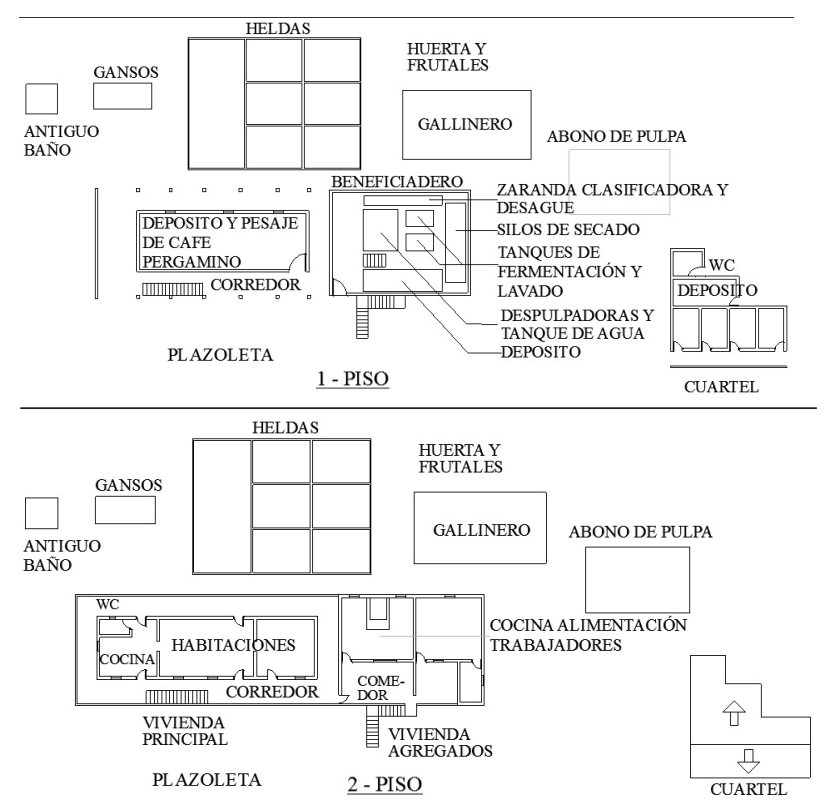

Figuras 9 y 10. Esquema espacial de la casa de la Finca la Soledad. Fuente: elaboración propia 


\section{Finca La Ermita}

La Ermita abarca territorios pertenecientes a las veredas La Plata y El Higuerón, el 30\% de su cultivo es variedad caturra y el $70 \%$ variedad Colombia, sin que quede rastro alguno del café arábigo. La Ermita produce anualmente 50.000 arrobas de café pergamino para exportación (Vélez, E. Entrevista $2005)^{8}$. Las despulpadoras y los tanques de fermentación y lavado contemporáneos, se encuentran hoy en el mismo lugar del beneficiadero original de la finca. Su cubierta está construida con estructura de guadua y teja de barro, los entrepisos madera y guadua. La espacialidad, las técnicas constructivas y los ornamentos, continúan con el lenguaje formal de la arquitectura de la zona.

La casa de la Ermita fue construida aproximadamente en 1876 (Figura 11), se encuentra en un excelente estado de conservación a pesar de las diferentes obras de mantenimiento de que ha sido objeto. El piso del corredor principal fue completamente sustituido mediante el empleo de tablón de arcilla cocida no vitrificada, material similar al original, con el fin de que la casa conservara la apariencia y la funcionalidad de sus orígenes. Algunas paredes han tenido que reconstruirse para evitar el colapso de las estructuras que soportan. Los nuevos tramos de muros se construyeron el ladrillo cocido, amarrado al bahareque primario existente.

La casa repite la noción espacial de la casa cafetera caldense (Figura 12): plazoleta de llegada, seguida por un corredor semipúblico que distribuye a los espacios internos y privados de una sola crujía en forma de L, donde el lado principal es la zona de habitaciones que remata en el extremo izquierdo con el comedor familiar y el lado menor de la L es utilizado como área de servicios y beneficiadero. El área posterior de la casa cuenta con un corredor de menor jerarquía y seguidamente una zona trabajo donde hay un cultivo de flores y el acceso a las oficinas de la hacienda, como área de trabajo separada de la zona común. Esta casa tiene

8 Vélez, Eugenio. Entrevista, Manizales, agosto de 2015.

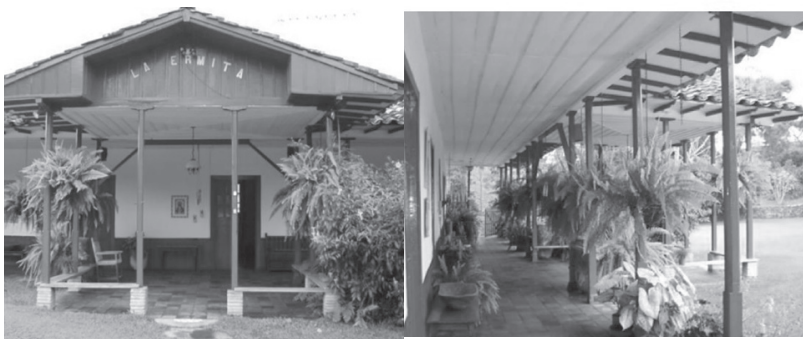

Figura 11. Fachada principal y corredor exterior de la casa de la Ermita. Fuente: elaboración propia

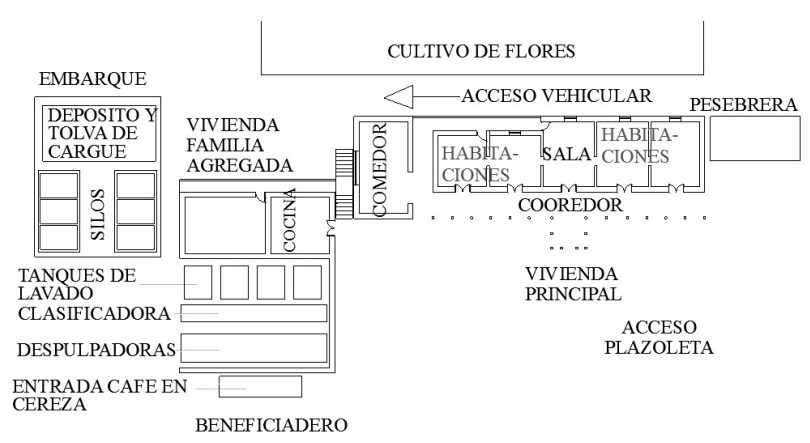

Figura 12. Esquema espacial de la casa de la Finca la Ermita. Fuente: elaboración propia

un acceso jerárquico muy marcado en centro de la crujía, muy utilizado en las "casas mayores" de las haciendas de la colonización de Caldas, sitio de recepción anterior al corredor, lugar con un carácter más público pero que generaba la posibilidad de la estancia de personas.

La ornamentación de puertas, ventanas y calados, emplean el lenguaje formal arquitectónico de la colonización antioqueña. El bahareque, la esterilla de guadua y la teja de barro, son los materiales predominantes de la construcción del inmueble. Los cielos rasos conforman figuras geométrica básicas, elaborados con tabla a tope y listones de madera como tapajuntas; todos elementos heredados y reproducidos hasta hoy en Caldas como repertorio formal propio de la zona.

\section{Pequeños caficultores: vereda La Pola}

La vereda La Pola pertenece al corregimiento Agroturístico (antes La Siria), el cual según el documento diagnóstico de los corregimiento 
de Manizales (Alcaldía de Manizales, 2013), contaba con 4.819 habitantes en el año 2013. La Pola, ubicada al sur del municipio de Manizales, es una centralidad lineal que se extiende sobre el borde de la carretera que distribuye hacia las diferentes parcelas. Cada minifundio es habitado por la familia propietaria, cuenta con casa de habitación, beneficiadero y cultivo de café. La mayoría de estos predios no exceden las dos hectáreas y en la producción de café intervienen activamente todos los miembros de la familia. La siembra, recolección y beneficio del café en La Pola mantiene una de las formas menos tecnificadas de producción cafetera, es una muestra del proceso de beneficio en caldas, que repite tipos de infraestructura, métodos y técnicas desde finales del siglo XIX.

La tecnificación del cultivo de los años 70 en Colombia cambió el café arábigo a variedades Caturra y Colombia, las cuales no requieren bosques de sombrío, transformando radicalmente el paisaje de principios del siglo XX. La poca tecnificación que han sufrido los cafetales de La Pola, así como otras veredas de la zona cafetera, hacen de estos poblados rurales, bienes con un alto grado de conservación cultural en todos sus ámbitos, desde la arquitectura, los modos de producción hasta las costumbres y las manifestaciones inmateriales del patrimonio cultural cafetero.

\section{Patrimonio natural de La Pola}

Los bajos niveles de tecnificación y el módico uso de agroquímicos, han permitido la conservación de la flora y la fauna de la región. Las numerosas especies de mariposas, por ejemplo, son un indicador biológico de calidad ambiental (Corpocaldas, 2007). La zona es entonces un lugar que mantiene vivo el rico patrimonio natural de los Andes colombianos, que junto con la vasta herencia material e inmaterial, conforman un patrimonio mixto capaz de expresar la identidad cultural cafetera caldense en toda su magnitud (Figuras 13 y 14).

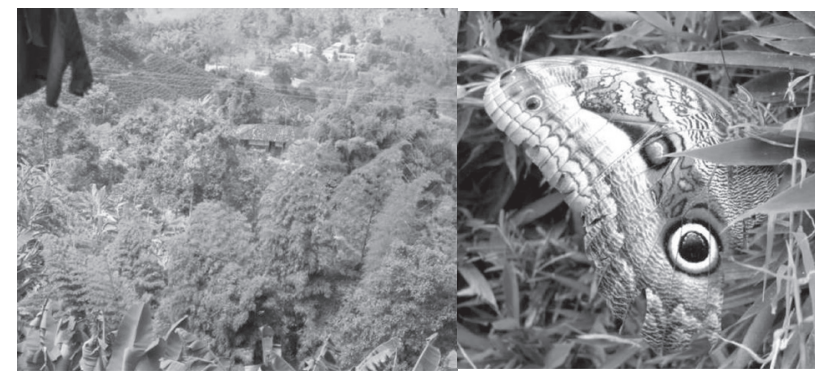

Figuras 13 y 14. Bosques, sombrío del café arábigo y mariposa búho. Fuente: elaboración propia

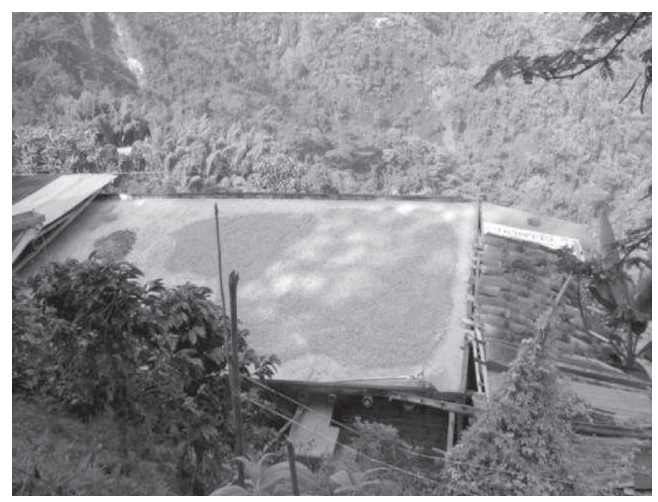

Figura 15. Helda de café en la vereda la Pola. Fuente elaboración propia

Producción y beneficio en La Pola: Los inmuebles y elementos constitutivos de los beneficiaderos (Figura 15) y de la infraestructura interna de las fincas están llenos de ingenio y versatilidad constructiva. Los materiales de la zona, que igualmente son utilizados en todos los tipos de construcciones de la región, como la guadua, la madera, la teja de barro, la macana y el bahareque; son elementos constantes en la transmisión de conocimientos de generación en generación. Estas construcciones son complementadas con adiciones de materiales contemporáneos como el cemento, las tejas de zinc y tejas de fibrocemento. Los conceptos de espacialidad y usos se mantienen en la arquitectura como herencia viva de la colonización antioqueña.

Las estructuras en madera y guadua, se adaptan a la topografía de cada finca, al tamaño del predio disponible para la construcción y al volumen de producción. Las viviendas contienen los beneficiaderos en semisótanos o en estructuras anexas, estas unidades productivas están construidas con 


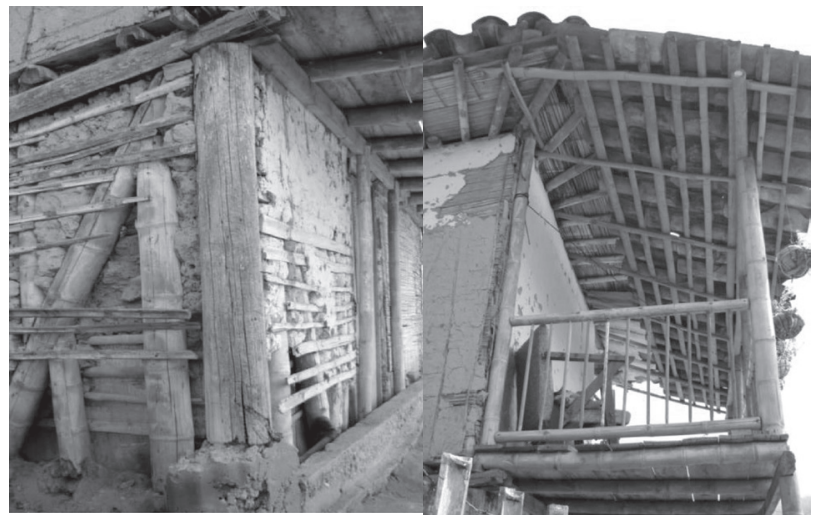

Figuras 16 y 17. Estructuras de guadua y arboloco, muros de bahareque y cagajón y esterilla de guadua. Fuente: elaboración propia

estructuras de guadua y arboloco ${ }^{9}$, muros de bahareque -cagajón y esterilla de guadua y cubiertas de guadua y teja de barro (Figuras 16 y 17). s

\section{Las casas de La Pola}

De diversas variaciones pero sin excepción, la vivienda campesina de esta vereda responde a la concepción espacial de la casa cafetera: un acceso de plazoleta, (en ocasiones no permite el acceso vehicular), sigue siendo espacio abierto de carácter público, seguido un corredor semipúblico que es lugar de reunión y estancia; distribuye linealmente hacia las habitaciones privadas que internamente se comunican por vanos abiertos casi siempre en los centros de los muros. Crujías de un solo lado o en forma de L principalmente, conforman la casa que casi siempre cuenta con un corredor posterior secundario que permite la observación del paisaje y el control de las labores de la finca. En la parte posterior o en los semisótanos con acceso posterior se encuentran los beneficiaderos, heldas,

9 El arboloco (Smallanthus pyramidalis) fue compañero inseparable de la guadua en la construcción de la vivienda rural, lo mismo que en la infraestructura para el café.(...) con longitudes hasta de 20 metros o más, y con diámetros frecuentes de 25 centímetros o más, (...)como viga maestra para el soporte del techo o de los pisos en cualquier tipo de construcción(...). (Facultad de Ciencias Agropecuarias, Universidad de Caldas, 2018)

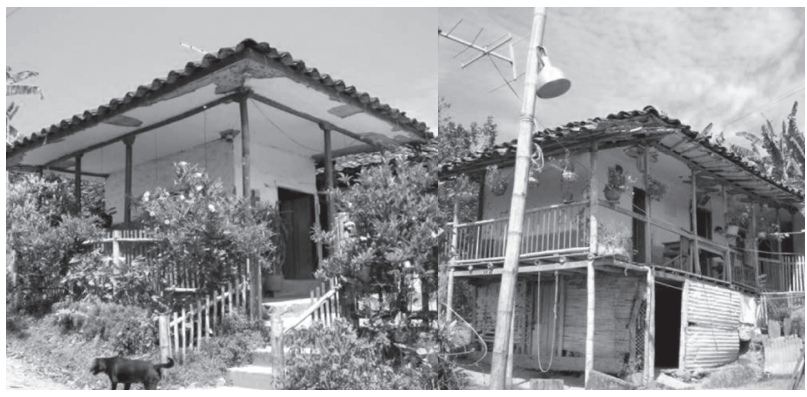

Figuras 18 y 19. Casas de La Pola construidas a finales del siglo XIX. Fuente: elaboración propia

gallineros y todos los espacios para las labores productivas (Figuras 18 y 19).

Los paisajes son el elemento constante de la cotidianidad de los pobladores; éste hace parte indeleble de su identidad cultural. Los caminos, las viviendas, los sitios de trabajo, los lugares de reunión, una topografía agreste, son el escenario natural de la vida y la actividad humana en La Pola. A través de corredores, puertas o ventanas, se observa un paisaje lleno de naturaleza y trabajo humano. La arquitectura se convierte así en el marco de un exterior integrador del patrimonio natural y cultural. En este sentido los corredores también constituyen esos lugares semipúblicos, sitio de reunión desde donde se observa el paisaje. (Figura 20).

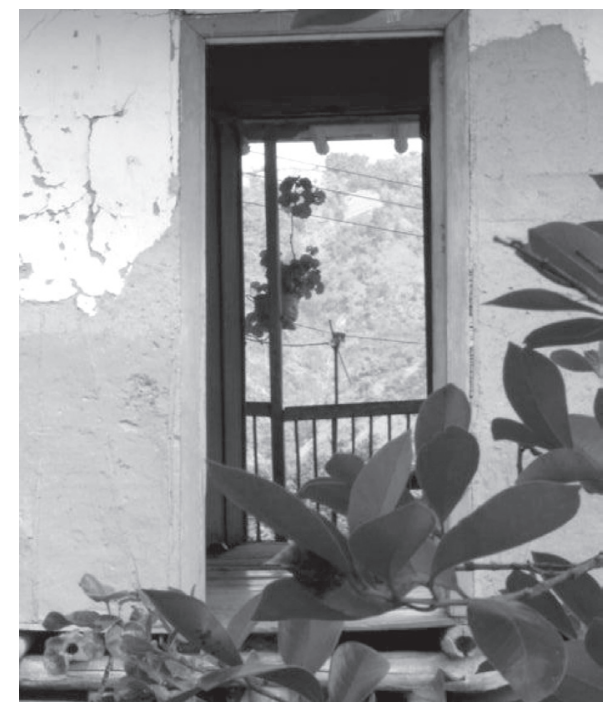

Figura 20. Casa de La Pola. El paisaje observado a través de la arquitectura. Fuente: elaboración propia 


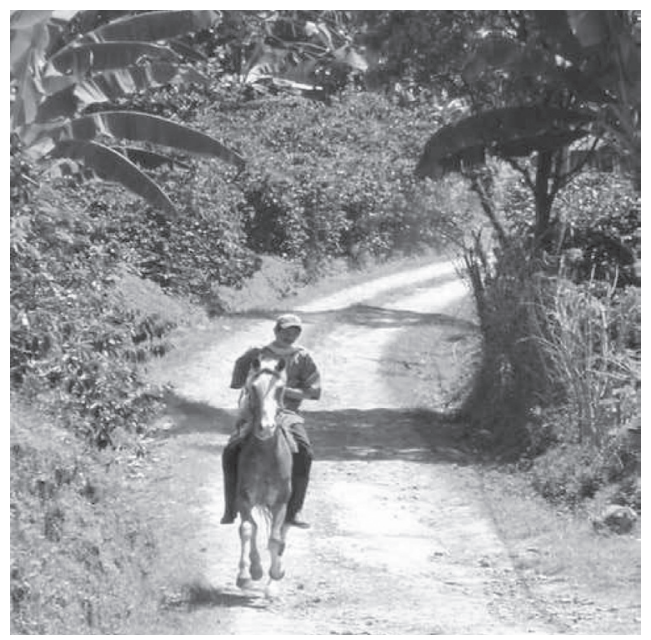

Figuras 21. El camino de La Pola. Fuente: elaboración propia

Otro elemento que vale la pena mencionar es la carretera de La Pola, como centralidad lineal, lugar principal de la movilidad y la comunicación de la vereda. Fue un camino de herradura usado en la penetración de la colonización antioqueña de mediados del siglo XIX; un siglo más tarde la vía se amplió con la llegada de los Jeeps Willys. El tránsito por este camino proporciona un recorrido ecológico y cultural (Figura 21).

\section{EI PCC y las actuales preocupaciones}

Una vez puesto en valor el patrimonio de la vivienda cafetera como unidad productiva, que además se encuentra dentro de las zonas principales y de amortiguamiento $^{10}$ del PCC, es conveniente hablar sobre el panorama actual de su conservación. A solo siete años de su inclusión en la lista mundial de la UNESCO, la preocupación por la pérdida de valores patrimoniales está creciendo entre acadé-

10 El área principal está constituida por 411 veredas (...) El área de amortiguamiento está constituida por 447 veredas y tiene una extensión de 207.000 hectáreas, así como por 17 cascos urbanos o cabeceras municipales, incluidos los que rodean los centros históricos o bienes de interés cultural mencionados. Área de amortiguamiento rural: 204.542 hectáreas. Área de amortiguamiento urbana: 2.458 hectáreas. (Paisajeculturalcafetero.org.co, 2018) micos y gestores culturales de la región. A los riesgos preexistentes tales como la implementación de nuevas técnicas de la agricultura cafetera, la falta de relevo generacional y la baja en los precios del café que pudieran desestimular su producción, se suma el turismo como una amenaza que está transformando rápidamente las expresiones culturales del PCC y por consiguiente del patrimonio agroindustrial cafetero de la región.

En este sentido, Duis (2018) afirma que si bien el incremento del turismo en la región está generando inversiones que pudieran conservar el patrimonio cultural, existe el riesgo de que esté siendo sometido al gusto del consumidor turístico, mercantilizando el patrimonio y la cultura, lo que puede llevar a la distorsión de los contenidos, afectando los valores y significados auténticos, utilizando "estereotipos más vendibles" que llevan a la falsificación, desfiguración o alteración del patrimonio, dando más importancia al producto de consumo.

Ramírez y Saldarriaga (2013) anotan que los usos de las vivienda de estas fincas han quedado a la orden de la oferta para que sea usada por los clientes, donde son necesarias las reconfiguraciones espaciales, la construcción de adiciones e instalaciones para los nuevos usos turísticos.

En un artículo del periódico El Tiempo (2015) se retoman algunas palabras de la profesora Duis en las que la estudiosa afirma que el PCC hoy parece corresponder a "paisajes en vía de extinción" pues "las fincas que ofrecen las comodidades de las casas de la ciudad. No son las fincas cafeteras de antes, tienen piscinas, canchas y eso no hace parte de los valores que tuvo en cuenta la Unesco" lo que por lo tanto corresponde más bien a la "folclorización" o "turistización" de la cultura cafetera, tal como lo anota Sepúlveda (2015).

En ese sentido, Mayorga (2015) en su trabajo Paisaje Cultural Cafetero, Patrimonio de la Humanidad. La cuestión del discurso patrimonial en contraste con el paisaje de la caficultura, encuentra que uno de los propósitos tácitos de la declaratoria que va en concordancia con el discurso patrimonial de 
la institucionalidad (Ministerios de Cultura, de Comercio, Industria y Turismo, entidades territoriales del Gobierno Nacional y el gremio caficultor) ha sido la introducción del turismo para proyectar la región como un destino de clase mundial, avalando e incentivando la oferta hotelera en la zona, para así usufructuar su patrimonio cultural y familiar, justificando la comercialización de la cultura como una oportunidad de crecimiento económico; posibilitando lo que se conoce como capitalismo cultural. Entendiendo así el discurso del paisaje cultural cafetero como una expresión del modelo neoliberal, pasando del paisaje agrícola al agro-turismo o mercancías culturales.

Ramírez y Saldarriaga (2013) ponen de presente existencia de la instrumentalización del PCC por parte del gobierno y de la organización gremial para ofrecerlo como una expresión de la voluntad general de la comunidad, escenificando el patrimonio cafetero mediante la artificialización a favor de sectores reducidos, lo que deriva en la pérdida de usos y significados que vinculan a los legítimos propietarios y gestores de la sociedad con su patrimonio. Esta teatralización consiste en el esfuerzo por simular que hay un origen, una sustancia fundante, donde son suprimidos del escenario los elementos sociales que resultan incómodos o inoperantes, es decir excluyendo a los actores locales que no puedan adaptarse a las condiciones nuevas del mercado turístico. Es así como la patrimonialización se convierte en una pretendida estrategia de conservación que pone en riesgo aquello que debe conservarse. Aclaran que la instrumentalización de la cultura genera un desarrollo desigual entre los cafeteros, ya que, los pequeños caficultores o campesinos asalariados no entrarían a formar parte de la oferta turística y su rentabilidad.

En este punto, la transformación cultural de las zonas declaradas en el PCC es más que notoria; la declaratoria ha traído consigo las miradas del turismo extranjero y Nacional, fenómeno que fue posible con la nueva imagen de pacificación que se le otorgó al país en los últimos años. No obstante el actual dinamismo de la economía de la zona cafetera en Colombia es innegable, esta veloz mutación cultural, le ha pasado una costosa factura al patrimonio cultural material e inmaterial que precisamente le otorga el valor excepcional por el cual fue declarado.

Ramírez y Saldarriaga (2013) sostienen que el discurso de rescate patrimonial del PCC, da paso a la dinámica de oferta y demanda, contribuyendo a la desnaturalización del patrimonio, atentando y presionando sus valores materiales, como el patrimonio arquitectónico y materiales como el bahareque, que se encuentran en un proceso de cambio debido a los nuevos usos y consumos, nuevas prácticas constructivas, nuevos espacios asociados al turismo y la inserción de lugares ficticios que idealizan la tradición cafetera. Los autores además denotan que existe evidencia en la transformación de las fincas en espacios de recepción de visitantes, como alojamientos rurales o productos turísticos tipo parque temático, motivando adicionalmente la especulación inmobiliaria. Todas estas son intervenciones gestionadas por actores sin vínculo directo con el patrimonio que no reproducen los valores del bien.

La vasta herencia del patrimonio agroindustrial de la zona cafetera, yace sobre una base física que constituye su patrimonio material; su arquitectura, los objetos, las máquinas, los lugares. La arquitectura de la colonización antioqueña y los materiales y técnicas de construcción de la zona: el bahareque de tierra y cagajón y cubiertas de tejas de barro, su ornamentación de calados y tablas de madera superpuestas, que conforman todo un lenguaje formal único en el mundo. Esta excepcional arquitectura, lleva en sí misma la tradición de los modos de construcción y la configuración espacial particular de las casas y lugares de beneficio, que dan cuenta de la memoria de trabajo, la estructura familiar y social, su economía y costumbres; es decir la memoria y la herencia inmaterial. Sin esta materialidad, no sería posible entender la cultura cafetera. Por ello, al desvirtuar la materialidad del patrimonio construido, modificando, mutilando y 
transformando la arquitectura del lugar, se están perdiendo las páginas de un documento histórico que no es posible leer más.

\section{A manera de conclusión}

Las expresiones culturales de la zona cafetera en Caldas, están claramente determinadas por su actividad productiva y por la herencia de la colonización antioqueña. El patrimonio agroindustrial del departamento es una rica fuente de documentación histórica que nos permite ahora y más tarde, a las futuras generaciones, entender nuestra sociedad y su desarrollo económico, cultural, social, político, tecnológico y científico. La preservación de este patrimonio cultural depende directamente de la continuidad de la industria del café como actividad económica rentable en todos los niveles de producción, desde las comunidades veredales como La Pola, hasta los medianos y los grandes productores, fincas como La Soledad y La Ermita.

En el caso del cambio radical que sufrió el paisaje cafetero en 1970 con la tecnificación de cultivos al pasar del café arábigo a la variedad caturra y luego a la variedad Colombia, aún quedan huellas aisladas de los antiguos cafetales con sombrío, que conservan la biodiversidad de flora y fauna propias de la región, conformando un rico patrimonio natural, sin embargo se requiere adelantar gestiones que estén encaminadas a crear áreas de conservación de cafetales antiguos (café arábigo con sombrío), conservando así, la arquitectura, las tecnologías de producción y beneficio, las técnicas constructivas y los materiales de la zona. Y algunos minifundios como los encontrados en la vereda $\mathrm{La}$ Pola, podrían ser unas de estas áreas a conservar, debido a que cuentan con todos los elementos que caracterizan el patrimonio agroindustrial cafetero; bienes de interés cultural que permiten leer con claridad el patrimonio en todas sus dimensiones y que son base fundamental para la conservación de la identidad cultural de la región.

Sin duda, la más inminente acción que debe llevarse a cabo con fines de preservación del acervo cultural, es la introducción de normativas completas y claras sobre las intervenciones de los bienes de interés cultural del PCC, su aplicación y su respectivo control. Los bienes y zonas incluidos en la declaratoria mundial, deben estar declarados en su totalidad como bienes de interés cultural del ámbito nacional, herramienta jurídica con la cual podría protegerse de manera más eficiente este patrimonio. Pues el patrimonio cultural de la zona cafetera de Colombia, está siendo amenazado por las abruptas transformaciones físicas a las que está siendo sometido en aras de satisfacer la creciente demanda de turismo. Si bien el turismo patrimonial-cultural debe ser aquel que se adapta, aprende y disfruta de las realidades del lugar, es este caso, es el lugar el que se está intentando adaptar constantemente a los requisitos del turismo. Esta desafortunada circunstancia podría estar dada por la manera en la que se ha promocionado el turismo del PCC y por la falta de una normativa clara y control sobre las intervenciones que se están haciendo en los bienes muebles y lugares de interés cultural.

Las acciones no reguladas como los falsos históricos, inclusión de ornamentación postiza y desvirtualización de los espacios interiores, derivan en la pérdida de valores físico-espaciales y culturales, que ponen en riesgo la conservación de la memoria histórica del patrimonio agroindustrial cafetero y de la colonización antioqueña en esta zona del país, así como la posibilidad única de aportar a la construcción la identidad cultural en Colombia.

\section{Referencias bibliográficas}

Aguilar Civera, I. (1998). Arquitectura industrial, Conceptos, Método y Fuentes. Valéncia, España: Editor Museu d'Etnologia de la Diputació de Valencia.

Alcaldía de Manizales (2013). Plan de ordenamiento territorial, Componente rural -Diagnostico corregimientos municipio de manizales- Revisión general del plan de ordenamiento territorial de mediano y largo plazo. Manizales, Colombia: Autor. 
Comité Internacional para la Conservación del Patrimonio Industrial, TICCIH (2003). Carta de Nizhny Tagil sobre el patrimonio industrial, Julio de 2003. Recuperado el 20/09/18, de https:// www.icomos.org/18thapril/2006/nizhny-tagilcharter-sp.pdf

Corporación Autónoma Regional de Caldas, CORPOCALDAS (2007). Plan de gestión Ambiental Regional del Municipio de Manizales, PGAR 2007-2019. Recuperado el 18/09/2018, de http://www.corpocaldas.gov.co/ publicaciones/329/PGAR\%20\%202007-2019_ Completo.pdf

Duis, U. (2018). Apuntes para la construcción del turismo cultural a partir del análisis de la oferta cultural-patrimonial y su demanda por el sector turístico del Quindío. Turismo y Sociedad, XXII. Armenia, Colombia. DOI: https://doi. org/10.18601/01207555.n22.07

Facultad de Ciencias Agropecuarias - Universidad de Caldas (2018). Recuperado el 24/09/2018, de http://ciagrope.tripod.com/rn01.html

Federación Nacional de Cafeteros de Colombia. (2018). Recuperado el 24/09/2018, de https:// www.federaciondecafeteros.org

Londoño, J. (2002). El modelo de colonización antioqueña de James Parsons. Un balance historiográfico. Fronteras de la Historia, núm. 7, pp. 187-226. Bogotá, Colombia: Instituto Colombiano de Antropología e Historia.

Márquez, M. (2005). Cien años Caldas y Café: La Leyenda Apenas Comienza. Manizales, Colombia: Editorial Blanecolor.

Mayorga, C. D. A. (2015). Paisaje Cultural Cafetero, Patrimonio de la Humanidad. La cuestión del discurso patrimonial en contraste con el paisaje de la caficultura. Territorios, 32, 35-59. Doi: dx.doi.org/10.12804/ territ32.2015.02.
Ministerio de Cultura de Colombia (2011). Resolución 2079 de 2011 - 7 OCT 2011, "Por la cual se reconoce al Paisaje Cultural Cafetero de Colombia como Patrimonio Cultural de la Nación". Recuperado el 18/09/2018 de http:// www.mincultura.gov.co/prensa/noticias/Documents/Patrimonio/5.\%20Resoluci\%C3\%B3n\%20 2079\%20de\%202011\%20PCC.pdf

Ministerio de Cultura de Colombia. (2018). Recuperado el 18/09/2018 de http://www.mincultura. gov.co/areas/patrimonio/investigacion-y-documentacion/politicas-planes-y-programas/ Paginas/Paisaje-Cultural-Cafetero.aspx)

Organización de las Naciones Unidas para la Educación, la Ciencia y la Cultura, UNESCO. Recuperado el 18/09/2018 de https://whc. unesco.org/en/list/1121

Organización del Paisaje Cultural Cafetero. Recuperado el 18/09/2018 de http://paisaje culturalcafetero.org.co/contenido/zonas-quelo-integran

Parsons, J. J. (1961). La colonización Antioqueña en el occidente de Colombia; traducción de Emilio Robledo. Bogotá, Colombia: Banco de la República.

Ramírez, S. \& Saldarriaga, C. (2013). Usos y abusos del paisaje cultural cafetero: una reflexión desde el concepto de patrimonio. Jangwa Pana 12: (115 - 128). Recuperado el 24 /09/ 2018 de http://revistas.unimagdalena.edu.co/index.php/ jangwapana/article/view/776/713

Sepúlveda Hincapié, L. (04 de julio 2015). Preocupan riesgos del Paisaje Cultural Cafetero - Alarma por la oferta comercial y los recursos del Conpes. El Tiempo. Recuperado el 20/09/2018 de https:// www.eltiempo.com/archivo/documento/ CMS-16043615 